\title{
Metabolic Changes in Patients with Aneurysmal Subarachnoid Hemorrhage Apart from Perfusion Deficits: Neuronal Mitochondrial Injury?
}

\author{
M. Wagner, A. Jurcoane, C. Hildebrand, E. Güresir, H. Vatter, F.E. Zanella, J. Berkefeld, U. Pilatus, and E. Hattingen
}

\begin{abstract}
BACKGROUND AND PURPOSE: Neuronal damage in aSAH apart from perfusion deficits has been widely discussed. We aimed to test if cerebral injury occurs in aSAH independently from visible perfusion deficit by measuring cerebral metabolites in patients with aSAH without infarction or impaired perfusion.
\end{abstract}

MATERIALS AND METHODS: We performed 3T MR imaging including 'H-MR spectroscopy, DWI, and MR perfusion in 58 patients with aSAH and 11 age-matched and sex-matched control patients with incidental aneurysm. We compared changes of NAA, Cho, Glx, Lac, and Cr between all patients with aSAH and controls, between patients with and without visible perfusion deficit or infarction and controls, and between patients with and without visible perfusion deficit or infarction by using the Wilcoxon signed-rank test.

RESULTS: We found that NAA significantly $(P<.005)$ decreased in all patients with aSAH. Cho was significantly increased in all patients compared with controls $(P<.05)$. In patients without impaired perfusion or infarction, Glx was significantly decreased compared with both controls $(P=.005)$ and patients with impaired perfusion or infarction $(P=.006)$.

CONCLUSIONS: The significant decrease of NAA and Glx in patients with aSAH but without impaired perfusion or infarction strongly suggests global metabolic changes independent from visible perfusion deficits that might reflect neuronal mitochondrial injury. Further, impaired perfusion in aSAH seems to induce additional metabolic changes from increasing neuronal stress that might, to some extent, mask the global metabolic changes.

ABBREVIATIONS: ACA = anterior cerebral artery; aSAH = aneurysmal subarachnoid hemorrhage; DSC = dynamic susceptibility-weighted contrast-enhanced; $\mathrm{Glx}=$ glutamate + glutamine; $\mathrm{Lac}=$ lactate

C erebral dysfunction and delayed ischemic neurologic deficits are frequent complications of aneurysm rupture and increase the risk for a poor outcome. Neurologic sequelae of aSAH have been mainly attributed to impaired cerebral perfusion. ${ }^{1}$ According to this hypothesis, brain damage after aSAH should be most pronounced in hemodynamically impaired brain regions. However, increasing evidence exists that SAH itself induces brain damage, and cortical spreading depression with neuronal and glial mass depolarization wave may be an underlying mechanism. ${ }^{2-6}$

Received August 6, 2012; accepted after revision September 28.

From the Institute of Neuroradiology (M.W., A.J., C.H., F.E.Z., J.B., U.P., E.H.), and Department of Neurosurgery (E.G., H.V.), University Hospital, Goethe University, Frankfurt am Main, Germany.

M.W. and A.J. contributed equally to this manuscript.

Please address correspondence to Marlies Wagner, Institute of Neuroradiology, Goethe University Hospital, Schleusenweg 2-16, D-60528 Frankfurt am Main, Germany; e-mail: marlies.wagner@kgu.de

http://dx.doi.org/10.3174/ajnr.A3420
After SAH, patients frequently show cognitive or behavioral abnormalities that have no pathologic correlate in conventional MR imaging. ${ }^{7} \mathrm{H}-\mathrm{MR}$ spectroscopy allows noninvasive in vivo measurement of metabolic changes that are able to detect brain damage even in normal-appearing brain tissue. ${ }^{8-10}$ Cerebral metabolite changes could also be measured by ${ }^{1} \mathrm{H}-\mathrm{MR}$ spectroscopy after $\mathrm{SAH}$, even on morphologically normal MR imaging. ${ }^{1,7,11,12}$ Furthermore, Macmillan et $\mathrm{al}^{1}$ found chronic metabolic changes in patients after aSAH that might be compatible with the neurologic sequelae in patients with $\mathrm{SAH}$.

The brain metabolite NAA is a sensitive neuronal marker that is known to decrease in almost all cerebral diseases associated with neuronal injury. NAA is formed in neuronal mitochondria, so it is also considered a marker of mitochondrial integrity and function in neurons. ${ }^{13-20}$ Therefore, it might be also decreased in patients with decreased cerebral mitochondrial function without irreversible neuronal damage.

Apart from NAA, ${ }^{1} \mathrm{H}-\mathrm{MR}$ spectroscopy measures other metabolites such as the pooled Cho compounds as markers of membrane-related processes, the pooled Cr compounds as the sum of 
Cr and phosphocreatine, and Lac as a marker of anaerobe metabolism. Furthermore, the signal pattern Glx, which is attributed to the sum of glutamate and glutamine signals, is measurable especially at higher-field strengths.

Metabolic changes can be evaluated by use of MR spectroscopy, and perfusion changes can be measured by MR perfusion imaging in almost every region of the brain. This can be done in defined areas of the brain on the basis of the underlying anatomy and also in relationship to the vascular territories. The combination of these 2 imaging modalities seems adequate to investigate metabolite changes after aSAH in hemodynamically normal and impaired vascular territories of the brain.

The aim of our study was to test whether metabolic changes in patients with aSAH are limited to brain areas of impaired perfusion, or if a normally perfused brain is affected as well.

\section{MATERIALS AND METHODS Study Participants}

The study was approved by the local ethics committee, and informed consent was given from each participant. A total of 58 patients ( 42 women; aged $32-81$ years; mean age, 55 years) with acute aSAH and 11 control patients ( 8 women; aged $23-73$ years; mean age, 50 years) with incidental aneurysms were included in the study. MR imaging was done in each patient during the time window from initial bleeding until the individual end of occurrence of vasospasm ${ }^{21}$ and was repeated in case of clinical deterioration. Therefore, the time between MR imaging follow-up examinations, whenever necessary ( 28 of 58 patients had between 1 and 8 follow-ups [mean number of follow-ups, 2] between 3 and 21 days after bleeding), varied depending on each patient's individual clinical course.

\section{MR Imaging Examination}

MR imaging of the brain was performed on a 3T whole-body system (Magnetom Verio; Siemens, Erlangen, Germany) with an 8 -channel phased array head coil. The protocol included T2weighted images; $\mathrm{T}^{*}$-weighted images, single-shot echo-planar DWI $(b=1000)$ with apparent diffusion coefficient maps, MR angiography (3D multislight time-of-flight), and MR perfusion. For MR perfusion, DSC-MR imaging was performed after intravenous contrast agent injection $(0.05 \mathrm{mmol} / \mathrm{kg})$ of gadobutrol (power injector, flow rate of $5 \mathrm{~mL} / \mathrm{s}$ followed by a $20-\mathrm{mL}$ bolus of $0.9 \%$ saline with the same flow rate).

${ }^{1} \mathrm{H}$-MRS of the brain was performed on the same $3 \mathrm{~T}$ wholebody system by use of the same 8-channel phased array head coil. Sequence parameters were TR, $1500 \mathrm{~ms}$; TE, $35 \mathrm{~ms}$; field of view, $240 \times 240 \mathrm{~mm}^{2}$; matrix, $16 \times 16$; section thickness, 15 $\mathrm{mm}$; and duration, 04:45 minutes. The axial 2D MRS section (with a circular phase-encoding scheme) was acquired at the level of the centrum semiovale. The volume of interest was selected by use of a chemical shift imaging-semiLASER sequence, $^{22}$ which was provided by the vendor as a work-inprogress sequence. The target volume was adjusted to a size of $100 \times 70 \mathrm{~mm}^{2}$. Before Fourier transformation, the matrix was extrapolated to $36 \times 36$, resulting in a $7.5 \times 7.5 \mathrm{~mm}^{2}$ in-plane grid size (Fig 1).

\section{Processing}

${ }^{1} \mathrm{H}$-MRS. The ${ }^{1} \mathrm{H}$-MRS spectra were analyzed off-line. A graphical user interface developed at our institute was used for imageguided selection (based on the reference images) of the free induction decays from the aSAH data. The free induction decays were analyzed by use of the LCModel software ${ }^{23}$ (downloadable test version at: http://s-provencher.com), which simulates the spectra with a linear combination of model spectra and is considered to be the most suitable tool for analyzing short-TE spectra. ${ }^{24}$ Baseline correction was performed, including macromolecules. The Cramer-Rao lower bounds indicated by the program were used to measure the quality and reliability of the ${ }^{1} \mathrm{H}$ spectroscopic data, rejecting data with values below $20 \% .^{23}$ In addition, all spectra from the selected voxels were visually assessed for artifacts according to the criteria described by Kreis. ${ }^{25}$ Only spectra with adequate quality were included in the analysis. Metabolite intensities were referenced against a calibrated phantom. Concentrations are considered as laboratory units (a.u.), but their values in millimoles per liter $(\mathrm{mmol} / \mathrm{L})$ are in the order of published data.

Metabolite values (NAA, Cho, Glx, Cr) were averaged in 4 different arterial territories (left ACA, right ACA, left MCA, and right $\mathrm{MCA}$ ) according to the underlying anatomy. No attempt was made to exclude voxels with impaired perfusion or infarcted tissue. In patients with several follow-up MR studies, the metabolite values of all studies were averaged for each territory.

\section{DSC-MR Imaging}

To analyze the relative MTT from the perfusion MR imaging data, we used the in-built software syngo (Siemens) featuring standard algorithms applied to the first-pass data as described previously. ${ }^{26,27}$ MTT maps of the tracer were computed by means of the relationship specified by the central volume theorem: MTT $=$ $\mathrm{CBV} / \mathrm{CBF}^{27}$

Gray-scale relative MTT maps (Fig 1) were generated at the same level as the 2D MRS section and were aligned with the congruent DWI/apparent diffusion coefficient maps and T2weighted images to provide better visualization of infarcted areas. In each of the 4 regions of interest (ACA and MCA of both hemispheres), cerebrovascular impairment because of delayed perfusion ( $>2$ seconds of MTT delay compared with the contralateral healthy-appearing tissue $)^{28}$ or infarcted areas was identified by 2 experienced neuroradiologists on all imaging modalities.

\section{Data Analysis}

Four groups were defined: 1) all patients with $\mathrm{SAH}(n=58) ; 2)$ patients with SAH but without infarction or impaired perfusion $(n=12) ; 3)$ patients with SAH with infarction or impaired perfusion $(n=46)$; and 4$)$ controls $(n=11)$.

Metabolite concentrations (NAA, Cho, Glx, Cr) of each arterial territory (ACA and MCA of both hemispheres) were compared among groups: 1 vs. 4, 2 vs. 4,3 vs. 2 , and 3 vs. 4 (Table). Lactate was quantified visually in the original spectra. The presence of a clear positive doublet signal at $1.3 \mathrm{ppm}$ was taken as a marker for increased concentration of this metabolite. ${ }^{8}$ (Fig 1).

For all patients with SAH $(n=58)$, the NAA/Cho ratio was calculated. For the concentrations and the ratio, a correlation 

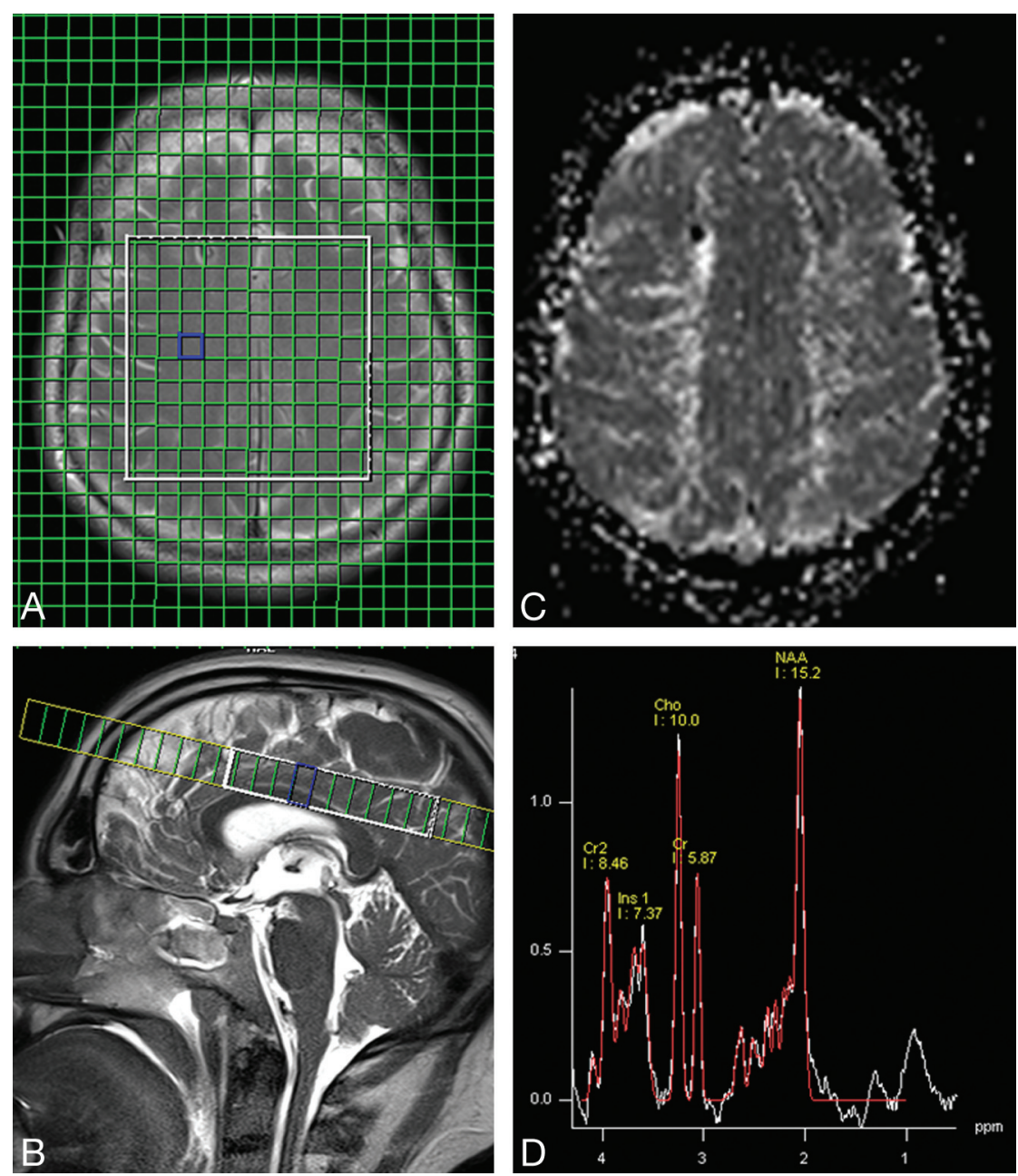

FIG 1. An axial 2D MRS section was acquired at the level of the centrum semiovale ( $A$ and $B$ ). For correlation with the spectroscopic data, gray-scale relative MTT maps $(C)$ were generated at the same level as the 2D MRS section. Lac was quantified visually in the original spectra $(D)$. No clear positive doublet signal at $1.3 \mathrm{ppm}$ (LaC) was found in any of the patients or controls.

(Spearman rho) vs the Hunt and Hess scale, which indicates the severity of acute symptoms after onset of SAH, was done (Fig 2).

\section{RESULTS}

Compared with controls, all patients with aSAH showed significant decrease in NAA globally and in each territory and significant increase in Cho globally and in the ACA territories. However, Glx showed significant changes only in the territory of the left MCA but not globally (Table).

Patients with SAH with impaired perfusion or infarction showed significant decrease in NAA globally and in each territory but no significant increase of Cho compared with controls (Fig 3, Table), and Glx was significantly decreased only in the territory of the left MCA but not in the other territories or globally (Table).

Patients with aSAH but without impaired perfusion or infarction also showed significant decrease of NAA globally and in each territory compared with controls. Cho was significantly increased in the territory of the right ACA only but not globally (Fig 3 ). However, significant decrease in Glx could be shown globally and in the territories of the left ACA and MCA (Table).

Compared with patients with aSAH but without impaired per- fusion and/or infarction, patients with aSAH with impaired perfusion or infarction showed significant increase in Glx globally and in the territories of the left ACA and MCA, but NAA and Cho did not show significant changes (Table).

We further found a significant correlation $(P<.05)$ between the NAA/Cho ratio and the Hunt and Hess scale (Spearman $R,-0.55)$ as a decrease in NAA and increased Hunt and Hess scale (Spearman $R,-0.36$ ), as well as an increase in Cho and increased Hunt and Hess scale (Spearman $R$, 0.27) (Fig 2).

$\mathrm{Cr}$ showed no significant changes between all patients with $\mathrm{SAH}$, patients with or without impaired perfusion or infarction, and controls in any territory or globally. There was a significant increase of $\mathrm{Cr}$ in patients with impaired perfusion or infarction in the territory of the left MCA only, whereas in all other territories and globally, no changes have been found. No Lac peaks were found in any of the 3 groups.

\section{DISCUSSION}

Our study reveals that patients with aSAH show significant metabolic changes, even in the absence of impaired perfusion or infarction. All patients with aSAH, including both groups with and without impaired perfusion or infarction, showed a significant decrease in NAA. Although Glx showed significant decrease only in patients with aSAH without impaired perfusion or infarction, a significant increase in Cho was found only in patients with aSAH with impaired perfusion or infarction. However, both metabolites showed a concordant trend in each other's group.

The brain metabolite NAA is a sensitive marker for neuronal integrity, function, and attenuation. Its concentration is very stable in healthy adults, ${ }^{13-19}$ so that decreasing NAA suggests neuronal damage. Consistent with our results, previous studies that used ${ }^{1} \mathrm{H}-\mathrm{MR}$ spectroscopy revealed significant decrease in NAA and increase in Cho in patients with aSAH. ${ }^{1,7,11,12,29}$ These authors believed that the decrease in NAA was mainly attributed to reversible and irreversible neuronal damage because of impaired perfusion resulting mainly from cerebral vasospasm.

To test this hypothesis, we are the first to measure metabolic changes in patients with aSAH without areas of infarction and/or impaired brain perfusion measured by DWI and perfusion measurement by DSC-MR imaging. Our results strongly suggest that the NAA decrease and decreased NAA/Cho ratio in patients with SAH cannot be explained by measureable impairment of cerebral perfusion related to cerebral vasospasm.

Neuronal damage in SAH apart from measureable impaired

AJNR Am J Neuroradiol 34:1535-41 Aug 2013 www.ajnr.org 


\begin{tabular}{|c|c|c|c|c|c|c|c|c|c|c|c|c|c|c|c|c|c|c|c|c|c|}
\hline \multirow[b]{2}{*}{ Territory } & \multirow[b]{2}{*}{ Side } & \multicolumn{4}{|c|}{$\begin{array}{l}\text { All SAH Patients } \\
(n=58) \text { vs Controls }\end{array}$} & \multicolumn{4}{|c|}{$\begin{array}{l}\text { SAH without } \\
\text { Impairment } \\
\text { ( } n=12) \text { vs Control }\end{array}$} & \multicolumn{4}{|c|}{$\begin{array}{c}\text { SAH with } \\
\text { Impairment }(n=46) \\
\text { vs SAH without } \\
\text { Impairment }\end{array}$} & \multicolumn{4}{|c|}{$\begin{array}{c}\text { SAH with } \\
\text { Impairment } \\
(n=46) \text { vs Controls }\end{array}$} & \multicolumn{4}{|c|}{$\begin{array}{l}\text { Controls without } \\
\text { SAH }(n=11)\end{array}$} \\
\hline & & NAA & Glx & Cho & $\mathrm{Cr}$ & NAA & Glx & Cho & $\mathrm{Cr}$ & NAA & Glx & Cho & $\mathrm{Cr}$ & NAA & Glx & Cho & $\mathrm{Cr}$ & NAA & Glx & Cho & $\mathrm{Cr}$ \\
\hline \multirow[t]{2}{*}{ ACA } & Right & $\begin{array}{l}* 9.67 \\
*(.00)\end{array}$ & $\begin{array}{l}11.61 \\
(.61)\end{array}$ & $\begin{array}{l}* 2.71 \\
*(.04)\end{array}$ & $\begin{array}{l}8.18 \\
(.5)\end{array}$ & $\begin{array}{l}* 9.76 \\
*(.02)\end{array}$ & $\begin{array}{l}10.7 \\
(.13)\end{array}$ & $\begin{array}{l}* 2.96 \\
*(.01)\end{array}$ & $\begin{array}{l}8.3 \\
(.8)\end{array}$ & $\begin{array}{l}9.65 \\
(.84)\end{array}$ & $\begin{array}{l}11.84 \\
(.12)\end{array}$ & $\begin{array}{l}2.64 \\
(.05)\end{array}$ & $\begin{array}{l}8.15 \\
(.7)\end{array}$ & $\star(.00)$ & $(.85)$ & $(.07)$ & (.43) & 11.56 & 11.97 & 2.39 & 8.44 \\
\hline & Left & $\begin{array}{l}* 9.98 \\
*(.02)\end{array}$ & $\begin{array}{l}11.64 \\
(.16)\end{array}$ & $\begin{array}{l}* 2.77 \\
*(.06)\end{array}$ & $\begin{array}{l}8.28 \\
(.39)\end{array}$ & $\begin{array}{l}* 9.61 \\
*(.04)\end{array}$ & $\begin{array}{l}* 9.98 \\
*(.01)\end{array}$ & $\begin{array}{c}2.9 \\
(.07)\end{array}$ & $\begin{array}{l}7.91 \\
(.25)\end{array}$ & $\begin{array}{r}10.07 \\
(.49)\end{array}$ & $\begin{array}{l}* 12.08 \\
*(.01)\end{array}$ & $\begin{array}{l}2.73 \\
(.4)\end{array}$ & $\begin{array}{l}8.37 \\
(.29)\end{array}$ & ${ }^{*}(.01)$ & & & & 11.55 & 12.82 & 2.41 & 8.64 \\
\hline \multirow[t]{2}{*}{ MCA } & Right & $\begin{array}{c}9.24 \\
*(.00)\end{array}$ & $\begin{array}{l}9.06 \\
(.37)\end{array}$ & $\begin{array}{l}2.28 \\
(.09)\end{array}$ & $\begin{array}{l}6.61 \\
(.63)\end{array}$ & $\begin{array}{l}* 9.33 \\
*(.03)\end{array}$ & $\begin{array}{l}8.26 \\
(.08)\end{array}$ & $\begin{array}{c}2.4 \\
(.09)\end{array}$ & $\begin{array}{l}6.6 \\
(.7)\end{array}$ & $\begin{array}{l}9.22 \\
(.87)\end{array}$ & $\begin{array}{l}9.26 \\
(.14)\end{array}$ & $\begin{array}{l}2.25 \\
(.35)\end{array}$ & $\begin{array}{l}6.61 \\
(.97)\end{array}$ & ${ }^{*}(.00)$ & (.55) & $(.10)$ & $(.61)$ & 11.13 & 9.64 & 2.02 & 6.78 \\
\hline & Left & $\begin{array}{l}* 10.34 \\
*(.01)\end{array}$ & $\begin{array}{c}* 10.22 \\
*(.02)\end{array}$ & $\begin{array}{l}2.71 \\
(.1)\end{array}$ & $\begin{array}{l}7.84 \\
(.38)\end{array}$ & $\begin{array}{l}* 9.54 \\
*(.01)\end{array}$ & $\begin{array}{l}* 8.34 \\
*(.00)\end{array}$ & $\begin{array}{l}2.72 \\
(.26)\end{array}$ & $\begin{array}{l}7.16 \\
(.11)\end{array}$ & $\begin{array}{l}10.55 \\
(.15)\end{array}$ & $\begin{array}{l}* 10.73 \\
*(.00)\end{array}$ & $\begin{array}{r}2.71 \\
(.95)\end{array}$ & $\begin{array}{l}* 8.02 \\
*(.04)\end{array}$ & $\star(.01)$ & $*(.03)$ & $(.06)$ & $(.58)$ & 12.24 & 12.10 & 2.41 & 8.18 \\
\hline Global & & $\begin{array}{l}* 9.84 \\
*(.00)\end{array}$ & $\begin{array}{l}10.67 \\
(.12)\end{array}$ & $\begin{array}{l}* 2.63 \\
*(.04)\end{array}$ & $\begin{array}{l}7.76 \\
(.44)\end{array}$ & $\begin{array}{l}* 9.56 \\
*(.01)\end{array}$ & $\begin{array}{l}* 9.32 \\
*(.01)\end{array}$ & $\begin{array}{l}2.74 \\
(.07)\end{array}$ & $\begin{array}{l}7.49 \\
(.30)\end{array}$ & $\begin{array}{l}9.92 \\
(.53)\end{array}$ & $\begin{array}{l}* 11.03 \\
*(.01)\end{array}$ & $\begin{array}{l}2.6 \\
(.36)\end{array}$ & $\begin{array}{l}7.83 \\
(.33)\end{array}$ & $\star(.00)$ & $(.27)$ & $(.06)$ & $(.52)$ & 11.62 & 11.63 & 2.31 & 8.01 \\
\hline
\end{tabular}

Note:- $P$ values are indicated in brackets.

* Significant values.

perfusion has been discussed in the literature, pointing toward different focal and generalized pathophysiologic mechanisms contributing to neuronal damage. The neuronal damage in aSAH seems to be a multifactorial process that includes local toxic effects of the blood clots, inflammatory and thrombogenic changes, disturbances of the cerebral autoregulation, and changes of the microcirculation..$^{2,3,30-52}$ One key factor contributing to neuronal damage in aSAH is cortical spreading depression, which causes neuronal depolarization resulting in cytotoxic edema because of overstressing of adenosine triphosphate-dependent sodium and calcium pumps. Therefore, energy demand increases to regenerate the calcium and sodium pump function. Cerebral blood flow accordingly increases by vasodilation to augment the glucose and oxygen supply. From a physiologic standpoint, after neuronal repolarization, spreading oligemia occurs because of vasodilation. However, cerebral injury such as aSAH might lead to an inverse hemodynamic response with nitric oxide-resistance and spasm of the microcirculation, resulting in energy impairment and neuronal damage. Those pathologic changes, which might not be detectable with DSA and transcranial Doppler sonography, can be associated with or without measurable perfusion deficit. ${ }^{2,3,6,48,53-56}$ Cortical spreading depression might therefore be a main contributor to the metabolic changes in areas without visible impaired perfusion or infarction, as shown in our study.

It has to be further mentioned that NAA reduction might not only be caused by irreversible neuronal damage but also by neuronal dysfunction. NAA is formed by acetylcoenzyme A and aspartate in mitochondria. ${ }^{13,15-17,19}$ Therefore, NAA decrease in patients with aSAH might be caused by reduced NAA synthesis in functionally impaired neuronal mitochondria.

We could further show significant decrease in Glx in patients with aSAH without evidence of impaired perfusion or infarction, which, in contrast, was not detectable in patients with impaired perfusion or infarction.

The decrease of Glx shown in our study is another indication of impaired mitochondrial function in aSAH. Glutamate is produced from alpha-ketoglutarate, which is an intermediate in the citric acid cycle occurring in the mitochondrial matrix. Furthermore, glutamate can be used as an additional energy source besides glucose in aSAH. ${ }^{19,29}$ Therefore, the overall decrease of Glx might be a consequence of the impaired energy metabolism in
SAH. It has been shown that glutamate as a main component of Glx might be increasingly produced as an excitatory neurotransmitter in aSAH ${ }^{57}$ and to increases extracellularly in SAH in rats. ${ }^{58}$ However, ${ }^{1} \mathrm{H}$-MRS measures the pool of glutamate, and synaptic changes of the neurotransmitter might not be detected. The insignificant decrease in Glx in patients with impaired perfusion and infarction might be the result of the increasingly released excitatory neurotransmitter glutamate as a neuronal stress reaction.

We also found an increase in Cho signal that reached a level of significance in the group of all patients with aSAH, and no significant difference could be shown between such patients with or without impaired perfusion or infarction. Cho signal includes free Cho, phosphorylcholine, and glycerophosphocholine, all known to be substrates of membrane metabolism. Cho is increased in enhanced anabolic and/or catabolic processes of cell membrane lipids. ${ }^{1,7}$ Cho increases in neoplastic and in inflammatory diseases. ${ }^{1,59}$ Regarding patients with aSAH, Macmillan et al ${ }^{1}$ could show that Cho was chronically increased even in normal-appearing white matter, but they also showed a more pronounced increase of Cho in posthemorrhagic, probably glial T2 white matter changes. Glycerophosphocholine as a major part of the Cho signal is known to be attributed to membrane catabolism because of cell damage. ${ }^{1}$ Therefore, we hypothesize the increase in Cho in our study to be result of damage of neuronal membranes as well as activation of glial membrane anabolism. Our finding that increase in Cho concentration correlates positively with increasing Hunt and Hess grade (Fig 2) might support this thesis.

The role of $\mathrm{Cr}$, which is found in highest concentrations in astrocytes and oligodendrocytes, has not yet been fully understood. It is known that increased Cr suggests upregulated metabolism because phosphocreatine works as a short-term energy reservoir. However, it is still unclear whether there is another biochemical role for $\mathrm{Cr}^{1,60}$ in $\mathrm{SAH}$. We did not find significant changes of Cr between patients with SAH and controls.

Lac has been discussed as a sensitive marker of ischemic and hypoxic diseases of the brain, including mitochondriopathies and aSAH. ${ }^{1,20,61}$ Dunne et $\mathrm{al}^{29}$ found an increase in Lac in vitro early after initial bleeding of $\mathrm{SAH}$, which quickly returned to normal values because of washout effects. In our in vivo study, we did not find an increase in Lac in patients with SAH with or without perfusion deficits, neither in brain parenchyma nor in the CSF. ${ }^{20}$ 

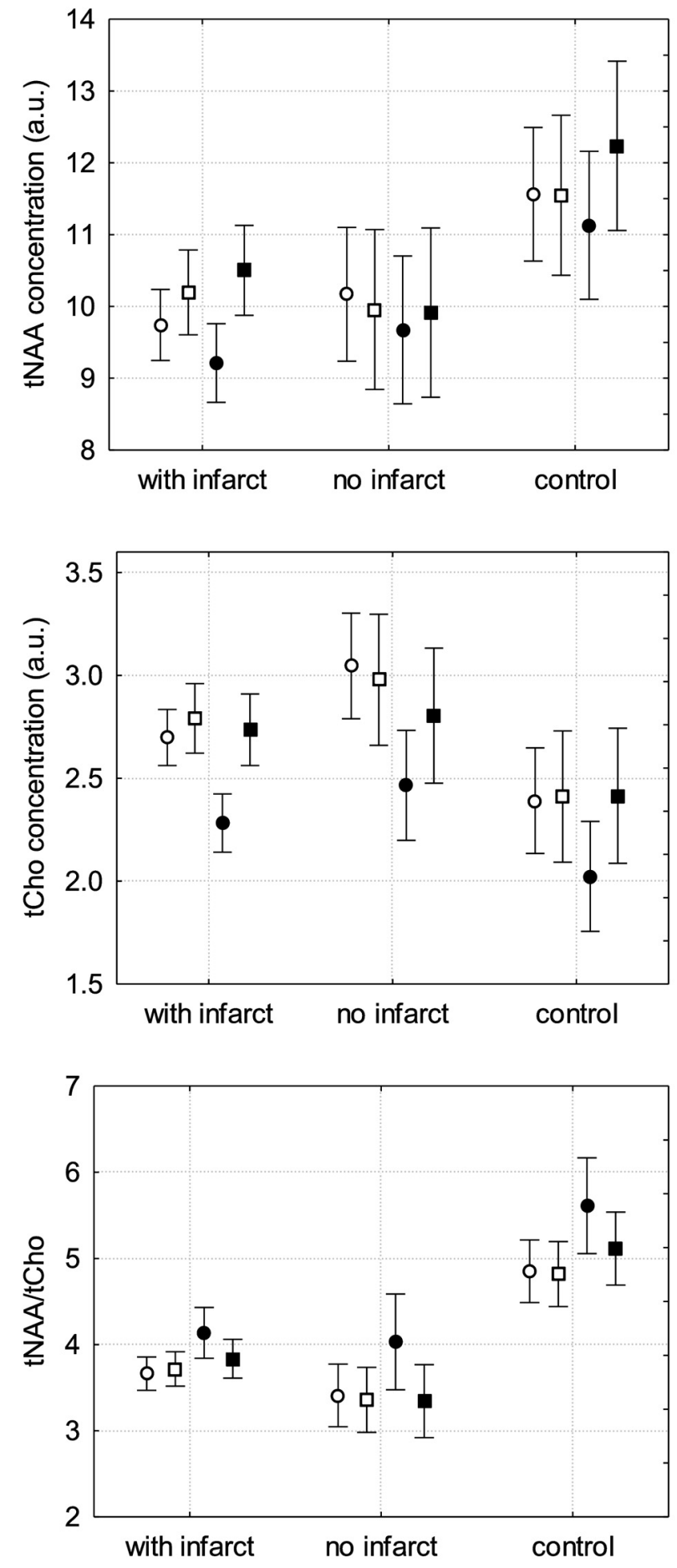

FIG 2. Distribution of NAA and Cho concentrations and NAA/Cho ratio in patients with aSAH with infarct or impaired perfusion, patients with aSAH without infarct or impaired perfusion, and in controls (white circle: ACA right; white square: ACA left; black circle: MCA right; black square: MCA left).

Our results coincide with previous studies ${ }^{1,7}$ and might be explained by the fact that the Lac increase after an initial event decreases very fast afterward. ${ }^{11,19}$

\section{Technical Limitations}

Quantitative metabolite values may be influenced by coil sensitivity profiles depending on their localization, ${ }^{62}$ whereas meta-
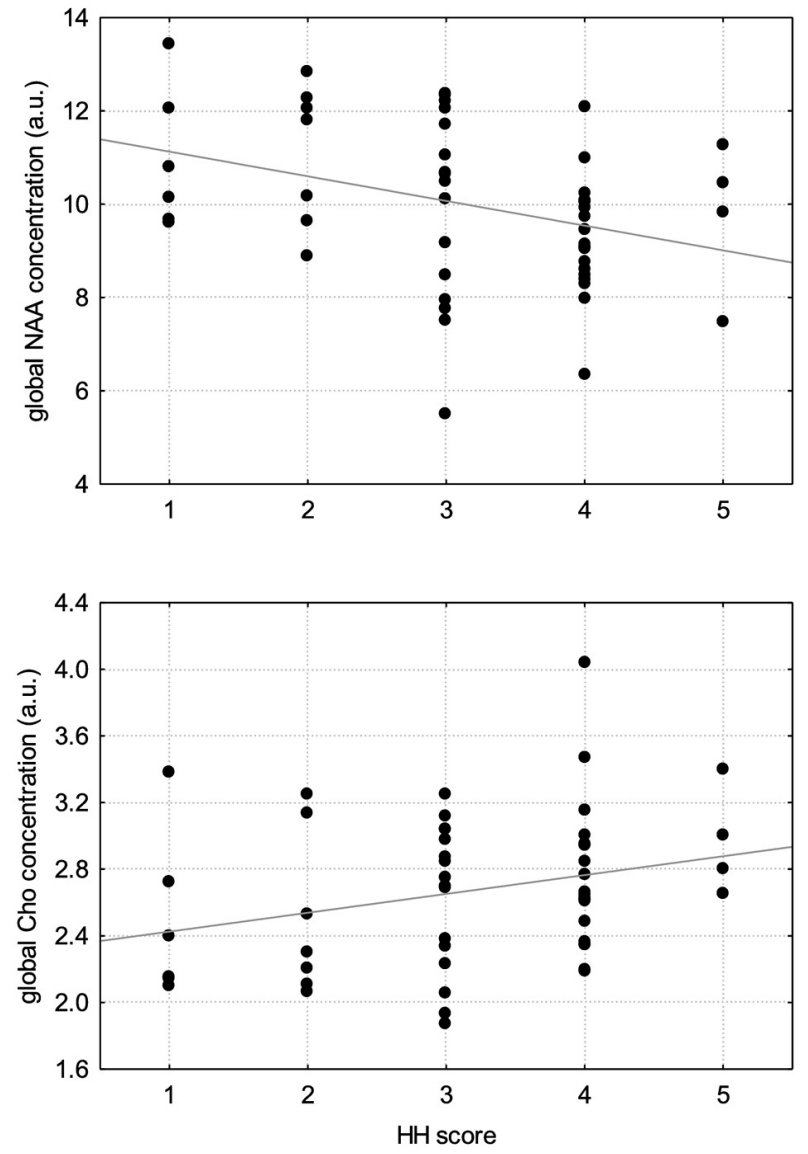

FIG 3. Correlation between NAA and Cho concentration and SAH score on the Hunt and Hess scale. The metabolite concentration reflects the average over all target areas and is therefore titled as a global concentration.

bolic ratios are not dependent on coil loading and pulse inhomogeneity.

We cannot exclude transient intervals of impaired perfusion before the MR imaging examination. ${ }^{63}$ However, our results show significant differences between patients with and without impaired perfusion. A sustained effect caused by a potential transient impaired perfusion before the MR imaging examination might have diminished the observed effect.

It is worth mentioning that our study is the first to compare MRS results of patients with aSAH exclusively vs patients with incidental aneurysms to exclude effects caused by the aneurysm itself.

\section{CONCLUSIONS}

We found metabolic changes in patients with aSAH with and also without impaired cerebral perfusion or infarction. In fact, metabolic changes were even more pronounced in patients without impaired perfusion or infarction vs patients with such changes. This finding implies global metabolic changes in patients with aSAH independent from visible perfusion deficits. The decrease in concentrations of NAA and Glx indicates that impaired mitochondrial function might be relevant for cerebral injury in aSAH. Furthermore, impairment of perfusion in aSAH seems to induce additional metabolic changes from increasing neuronal stress that might, to some extent, mask the global metabolic changes. 
Disclosures: Joachim Berkefeld_UNRELATED: Board Membership: advisory board member of Acandis company (Pforzheim, Germany); Payment for Development of Educational Presentations: invited lectures paid by Siemens (Forchheim, Germany).

\section{REFERENCES}

1. Macmillan CS, Wild JM, Wardlaw JM, et al. Traumatic brain injury and subarachnoid hemorrhage: in vivo occult pathology demonstrated by magnetic resonance spectroscopy may not be "ischaemic". A primary study and review of the literature. Acta Neurochir (Wien) 2002;144:853-62; discussion 862

2. Dreier JP, Ebert N, Priller J, et al. Products of hemolysis in the subarachnoid space inducing spreading ischemia in the cortex and focal necrosis in rats: a model for delayed ischemic neurological deficits after subarachnoid hemorrhage? J Neurosurg 2000;93:658-66

3. Dreier JP, Sakowitz OW, Harder A, et al. Focal laminar cortical MR signal abnormalities after subarachnoid hemorrhage. Ann Neurol 2002;52:825-29

4. Lauritzen M, Dreier JP, Fabricius M, et al. Clinical relevance of cortical spreading depression in neurological disorders: migraine, malignant stroke, subarachnoid and intracranial hemorrhage, and traumatic brain injury. J Cereb Blood Flow Metab 2011;31:17-35

5. Strong AJ, Macdonald RL. Cortical spreading ischemia in the absence of proximal vasospasm after aneurysmal subarachnoid hemorrhage: evidence for a dual mechanism of delayed cerebral ischemia. J Cereb Blood Flow Metab 2012;32:201-02

6. Woitzik J, Dreier JP, Hecht N, et al. Delayed cerebral ischemia and spreading depolarization in absence of angiographic vasospasm after subarachnoid hemorrhage. J Cereb Blood Flow Metab 2012;32: 203-12

7. Handa $Y$, Kaneko M, Matuda T, et al. In vivo proton magnetic resonance spectroscopy for metabolic changes in brain during chronic cerebral vasospasm in primates. Neurosurgery 1997;40:773-80; discussion 780-81

8. Hattingen E, Magerkurth J, Pilatus U, et al. Phosphorus and proton magnetic resonance spectroscopy demonstrates mitochondrial dysfunction in early and advanced Parkinson's disease. Brain 2009; 132:3285-97

9. Hattingen E, Magerkurth J, Pilatus U, et al. Combined (1)H and (31)P spectroscopy provides new insights into the pathobiochemistry of brain damage in multiple sclerosis. NMR Biomed 2011;24: 536-46

10. Blasel S, Pilatus U, Magerkurth J, et al. Metabolic gray matter changes of adolescents with anorexia nervosa in combined MR proton and phosphorus spectroscopy. Neuroradiology 2012;54:753-64

11. Schubert GA, Poli S, Schilling L, et al. Hypothermia reduces cytotoxic edema and metabolic alterations during the acute phase of massive SAH: a diffusion-weighted imaging and spectroscopy study in rats. $J$ Neurotrauma 2008;25:841-52

12. Rowe J, Blamire AM, Domingo Z, et al. Discrepancies between cerebral perfusion and metabolism after subarachnoid haemorrhage: a magnetic resonance approach. J Neurol Neurosurg Psychiatry 1998; 64:98-103

13. Rigotti DJ, Inglese $\mathrm{M}$, Gonen $\mathrm{O}$. Whole-brain $\mathrm{N}$-acetylaspartate as a surrogate marker of neuronal damage in diffuse neurologic disorders. AJNR Am J Neuroradiol 2007;28:1843-49

14. Rigotti DJ, Kirov II, Djavadi B, et al. Longitudinal whole-brain Nacetylaspartate concentration in healthy adults. AJNR Am J Neuroradiol 2011;32:1011-15

15. Arun P, Moffett JR, Namboodiri AM. Evidence for mitochondrial and cytoplasmic N-acetylaspartate synthesis in SH-SY5Y neuroblastoma cells. Neurochem Int 2009;55:219-25

16. Birken DL, Oldendorf WH. N-acetyl-L-aspartic acid: a literature review of a compound prominent in 1H-NMR spectroscopic studies of brain. Neurosci Biobehav Rev 1989;13:23-31

17. Ariyannur PS, Madhavarao CN, Namboodiri AM. N-acetylaspartate synthesis in the brain: mitochondria vs. microsomes. Brain Res 2008; 1227:34-41

18. Yan HD, Ishihara K, Serikawa T, et al. Activation by N-acetyl-L- aspartate of acutely dissociated hippocampal neurons in rats via metabotropic glutamate receptors. Epilepsia 2003;44:1153-59

19. Moffett JR, Ross B, Arun P, et al. N-Acetylaspartate in the CNS: from neurodiagnostics to neurobiology. Prog Neurobiol 2007;81:89-131

20. Bianchi MC, Sgandurra G, Tosetti M, et al. Brain magnetic resonance in the diagnostic evaluation of mitochondrial encephalopathies. Biosci Rep 2007;27:69-85

21. Kivisaari RP, Salonen O, Servo A, et al. MR imaging after aneurysmal subarachnoid hemorrhage and surgery: a long-term follow-up study. AJNR Am J Neuroradiol 2001;22:1143-48

22. Scheenen TW, Klomp DW, Wijnen JP, et al. Short echo time 1HMRSI of the human brain at $3 \mathrm{~T}$ with minimal chemical shift displacement errors using adiabatic refocusing pulses. Magn Reson Med 2008;59:1-6

23. Provencher SW. Automatic quantitation of localized in vivo $\mathbf{1} \mathbf{H}$ spectra with LCModel. NMR Biomed 2001;14:260-64

24. Kanowski M, Kaufmann J, Braun J, et al. Quantitation of simulated short echo time $1 \mathrm{H}$ human brain spectra by LCModel and AMARES. Magn Reson Med 2004;51:904-12

25. Kreis R. Issues of spectral quality in clinical $1 \mathrm{H}$-magnetic resonance spectroscopy and a gallery of artifacts. NMR Biomed 2004;17: 361-81

26. Ostergaard L, Weisskoff RM, Chesler DA, et al. High resolution measurement of cerebral blood flow using intravascular tracer bolus passages. Part I: mathematical approach and statistical analysis. Magn Reson Med 1996;36:715-25

27. Rosen BR, Belliveau JW, Vevea JM, et al. Perfusion imaging with NMR contrast agents. Magn Reson Med 1990;14:249-65

28. Vatter H, Güresir E, Berkefeld J, et al. Perfusion-diffusion mismatch in MRI to indicate endovascular treatment of cerebral vasospasm after subarachnoid haemorrhage. J Neurol Neurosurg Psychiatry 2011;82:876-83

29. Dunne VG, Bhattachayya S, Besser M, et al. Metabolites from cerebrospinal fluid in aneurysmal subarachnoid haemorrhage correlate with vasospasm and clinical outcome: a pattern-recognition $1 \mathrm{H}$ NMR study. NMR Biomed 2005;18:24-33

30. Sorensen AG, Copen WA, Ostergaard L, et al. Hyperacute stroke: simultaneous measurement of relative cerebral blood volume, relative cerebral blood flow, and mean tissue transit time. Radiology 1999;210:519-27

31. Fergusen S, Macdonald RL. Predictors of cerebral infarction in patients with aneurysmal subarachnoid hemorrhage. Neurosurgery 2007;60:658-67; discussion 667

32. Crowley RW, Medel R, Dumont AS, et al. Angiographic vasospasm is strongly correlated with cerebral infarction after subarachnoid hemorrhage. Stroke 2011;42:919-23

33. Rabinstein AA, Friedman JA, Weigand SD, et al. Predictors of cerebral infarction in aneurysmal subarachnoid hemorrhage. Stroke 2004;35:1862-66

34. Shimoda M, Takeuchi M, Tominaga J, et al. Asymptomatic versus symptomatic infarcts from vasospasm in patients with subarachnoid hemorrhage: serial magnetic resonance imaging. Neurosurgery 2001;49:1341-48; discussion 1348-50

35. Weidauer S, Lanfermann H, Raabe A, et al. Impairment of cerebral perfusion and infarct patterns attributable to vasospasm after aneurysmal subarachnoid hemorrhage: a prospective MRI and DSA study. Stroke 2007;38:1831-36

36. Weidauer S, Vatter H, Beck J, et al. Focal laminar cortical infarcts following aneurysmal subarachnoid haemorrhage. Neuroradiology 2008;50:1-8

37. Stein SC, Levine JM, Naqpal S, et al. Vasospasm as the sole cause of cerebral ischemia: how strong is the evidence? Neurosurg Focus 2006;21:E2

38. Koźniewska E, Michalik R, Rafałowska J, et al. Mechanisms of vascular dysfunction after subarachnoid hemorrhage. J Physiol Pharmacol 2006;57 Suppl 11:145-60

39. Lövblad KO, Wetzel SG, Somon T, et al. Diffusion-weighted MRI in cortical ischemia. Neuroradiology 2004;46:175-82 
40. Ohkuma $\mathrm{H}$, Itoh $\mathrm{K}$, Shibata $\mathrm{S}$, et al. Morphological changes of intraparenchymal arterioles after experimental subarachnoid hemorrhage in dogs. Neurosurgery 1997;41:230-35; discussion 235-36

41. Ohkuma H, Suzuki S. Histopathological dissocation between intraand extraparenchymal portion of perforating small arteries after experimental subarachnoid hemorrhage in dogs. Acta Neuropathol 1999;98:374-82

42. Dankbaar JW, Rijsdijk M, van der Schaaf IC, et al. Relationship between vasospasm, cerebral perfusion, and delayed cerebral ischemia after aneurysmal subarachnoid hemorrhage. Neuroradiology 2009;51:813-19

43. Rijsdijk M, van der Schaaf IC, Velthuis BK, et al. Global and focal cerebral perfusion after aneurysmal subarachnoid hemorrhage in relation with delayed cerebral ischemia. Neuroradiology 2008;50: $813-20$

44. Miranda P, Lagares A, Alen J, et al. Early transcranial Doppler after subarachnoid hemorrhage: clinical and radiological correlations. Surg Neurol 2006;65:247-52; discussion 252

45. Hattingen E, Blasel S, Dettmann E, et al. Perfusion-weighted MRI to evaluate cerebral autoregulation in aneurysmal subarachnoid haemorrhage. Neuroradiology 2008;50:929-38

46. Yundt KD, Grubb RL Jr, Diringer MN, et al. Autoregulatory vasodilatation of parenchymal vessels is impaired during cerebral vasospasm. J Cereb Blood Flow Metab 1998;18:419-24

47. Jaeger M, Schuhmann MU, Soehle M, et al. Continuous monitoring of cerebrovascular autoregulation after subarachnoid hemorrhage by brain tissue oxygen pressure reactivity and its relation to delayed cerebral infarction. Stroke 2007;38:981-86

48. Uhl E, Lehmberg J, Steiger HJ, et al. Intraoperative detection of early microvasospasm in patients with subarachnoid hemorrhage by using orthogonal polarization spectral imaging. Neurosurgery 2003; 52:1307-15; discussion 315-17

49. Wiernsperger N, Schulz U, Gygax P. Physiological and morphometric analysis of the microcirculation of the cerebral cortex under acute vasospasm. Stroke 1981;12:624-27

50. Chaudhary SR, Ko N, Dillon WP, et al. Prospective evaluation of multidetector-row $\mathrm{CT}$ angiography for the diagnosis of vasospasm following subarachnoid hemorrhage: a comparison with digital subtraction angiography. Cerebrovasc Dis 2008;25:144-50
51. Heuer GG, Smith MJ, Elliott JP, et al. Relationship between intracranial pressure and other clinical variables in patients with aneurysmal subarachnoid hemorrhage. J Neurosurg 2004;101:408-16

52. Grubb RL Jr, Raichle ME, Eichling JO, et al. Effects of subarachnoid hemorrhage on cerebral blood volume, blood flow, and oxygen utilization in humans. J Neurosurg 1977;46:446-53

53. Dreier JP, Woitzik J, Fabricius M, et al. Delayed ischaemic neurological deficits after subarachnoid haemorrhage are associated with clusters of spreading depolarizations. Brain 2006;129:3224-37

54. Dreier JP, Major S, Manning A, et al. Cortical spreading ischaemia is a novel process involved in ischaemic damage in patients with aneurysmal subarachnoid haemorrhage. Brain 2009;132:1866-81

55. Dreier JP. The role of spreading depression, spreading depolarization and spreading ischemia in neurological disease. Nat Med 2011; 17:439-47

56. Bosche B, Graf R, Ernestus RI, et al. Recurrent spreading depolarizations after subarachnoid hemorrhage decreases oxygen availability in human cerebral cortex. Ann Neurol 2010;67:607-17

57. Martinez-Hernandez A, Bell KP, Norenberg MD. Glutamine synthetase: glial localization in brain. Science 1977;195:1356-58

58. Wu CT, Wen LL, Wong CS, et al. Temporal changes in glutamate, glutamate transporters, basilar arteries wall thickness, and neuronal variability in an experimental rat model of subarachnoid hemorrhage. Anesth Analg 2011;112:666-73

59. Saini J, Chatterjee S, Thomas B, et al. Conventional and advanced magnetic resonance imaging in tumefactive demyelination. Acta Radiol 2011;52:1159-68

60. Hattingen E, Raab P, Franz K, et al. Prognostic value of choline and creatine in WHO grade II gliomas. Neuroradiology 2008;50:759-67

61. Domingo Z, Bradley JK, Blamire AM, et al. Diffusion weighted imaging and magnetic resonance spectroscopy in a low flow ischaemia model due to endothelin induced vasospasm. NMR Biomed 2000;13: $154-62$

62. Volz S, Nöth U, Rotarska-Jagiela A, et al. A fast B1-mapping method for the correction and normalization of magnetization transfer ratio maps at 3 T. Neuroimage 2010;49:3015-26

63. Wagner M, Steinbeis P, Güresir E, et al. Beyond delayed cerebral vasospasm: infarct patterns in patients with subarachnoid hemorrhage. Clin Neuroradiol 2013;23:87-95 